\title{
ENERGY HARVESTING WIRELESS SENSOR NETWORKS: DESIGN AND MODELING
}

\author{
Hussaini Habibu ${ }^{1}$, Adamu Murtala Zungeru², Ajagun Abimbola Susan ${ }^{3}$, Ijemaru \\ Gerald $^{4}$ \\ ${ }^{1,3}$ Department of Electrical and Electronics Engineering \\ Federal University of Technology Minna, Nigeria \\ ${ }^{2,4}$ Department of Electrical and Electronics Engineering \\ Federal University Oye-Ekiti, Nigeria
}

\begin{abstract}
Wireless sensor nodes are usually deployed in not easily accessible places to provide solution to a wide range of application such as environmental, medical and structural monitoring. They are spatially distributed and as a result are usually powered from batteries. Due to the limitation in providing power with batteries, which must be manually replaced when they are depleted, and location constraints in wireless sensor network causes a major setback on performance and lifetime of WSNs. This difficulty in battery replacement and cost led to a growing interest in energy harvesting. The current practice in energy harvesting for sensor networks is based on practical and simulation approach. The evaluation and validation of the WSN systems is mostly done using simulation and practical implementation. Simulation is widely used especially for its great advantage in evaluating network systems. Its disadvantages such as the long time taken to simulate and not being economical as it implements data without proper analysis of all that is involved, wasting useful resources cannot be ignored. In most times, the energy scavenged is directly wired to the sensor nodes. We, therefore, argue that simulation - based and practical implementation of WSN energy harvesting system should be further strengthened through mathematical analysis and design procedures. In this work, we designed and modeled the energy harvesting system for wireless sensor nodes based on the input and output parameters of the energy sources and sensor nodes. We also introduced the use of supercapacitor as buffer and intermittent source for the sensor node. The model was further tested in a Matlab environment, and found to yield a very good approach for system design.
\end{abstract}

\section{KEYWORDS}

Wireless Sensor Networks (WSNs); Mathematical Analysis; Energy Harvesting; Simulation.

\section{INTRODUCTION}

Wireless sensor networks (WSNs) are large networks consisting of small sensor nodes (SNs), with limited computing resources used to gather, process data and communicate. A major challenge in a lot of sensor network applications requires long period of life for network survival, which leads to high consumption of energy. The small sensor nodes are devices driven by battery and due to its high energy demand, the conventional low-power design techniques and structure cannot provide an adequate solution [1]. Wireless sensor nodes normally run on disposable batteries, which have a finite operating life. Based on the application and availability of potential ambient energy sources, using energy harvesting techniques to power a wireless sensor node is a wonderful thing to do. 
Wireless Sensor nodes have wide range of applications in our day to day activities. Ranging from a Bluetooth equipped chest band that convey human heart rate to a treadmill, wireless electrocardiograph (ECG) temporarily connected to communicate human cardiac activity to a doctor, Zigbee equipped smart meter that monitors energy usage in a household and provides feedback to the user for decision making [2]. In general, wireless sensor nodes applications include structural monitoring, industrial monitoring, security, location tracking, and radio frequency identification (RFID). These wireless sensor nodes will work efficiently for several years between battery replacements. This can be accomplished by the use of energy harvesting, utilizing ambient sources to prolong the life of the batteries in wireless sensor nodes.

Thin- film batteries are usually paired with a supercapacitor in order to handle the current surge when a wireless node transmits. As a result, supercapacitors are an unsubtle choice as energy buffers in energy harvesting applications. Unlike batteries, supercapacitors show extremely good cycle life and no issues relating to overcharge and over discharge. When the energy harvesting source is sufficient to meet the requirement of the wireless sensor node, then an adequately large supercapacitor may totally get rid of the need for a battery [1].

The energy harvesting system is made up of energy collection and energy storage. The collection part consists of the solar array. The energy storage device (supercapacitor), will as well serve as a power supply source to the SN. The sensor node in this project operates at RF $315 \mathrm{MHz}$ and is powered by a solar energy harvesting source. In order to properly power the sensor node, a supercapacitor of value $1.2 \mathrm{~F}$, and in most cases, operate at a voltage of 2.3 to 2 .

The objective of this work is to save cost by independently powering wireless sensor nodes with an energy harvesting source without the use of disposable batteries that require constant replacement. In situation where the batteries are still in use by sensor nodes, a supercapacitor allows the sensor node to transmit its final data to the sink node, in the event of power failure, preventing data loss and its associated problem. Sometimes, the system in question is not properly studied. Also, it will be wise enough to gain more knowledge of how the energy harvested degrades with time through system modeling.

The paper is organised as follows: The introductory part of the paper provided in Section 1, deals with the general perspective and objective of the work. Section 2 reviews relevant work in energy harvesting, energy harvesting power sources and energy storage. Section 3 gives a detailed explanation of the system design and implementation, which includes design specification, methodology, modeling of the supercapacitor discharge and sizing of the supercapacitor. The result of the modeling and its discussion was presented in Section 4. The conclusion and future work that to be done was presented in Section 5.

\section{REVIEW OF RELEVANT WORK IN ENERGY HARVESTING SYSTEM}

Aaron et al. [3] worked on a wireless sensing platform utilizing ambient RF energy. They work on an ambient RF energy harvesting sensor node, which has onboard sensing and communication characteristics, and the system was developed and tested. In a similar development, Authors in [4], work on conventional MEMS generators, nanogenerators, and show that they have an added advantage of being flexible and foldable power sources, and mostly suited in the implantable biomedical sensors applications. Several work were done ranging from energy harvesting power sources [2,5,6]. In [2], it was shown that, the thermal energy harvesting is based on seebeck effect, and the available voltage is approximated by 


$$
\mathrm{V}=\Delta \mathrm{S} * \Delta \mathrm{T}
$$

where $\Delta S$ represents seebeck coefficients of each metal and $\Delta T$ beeing the temperature difference between them.

A summary of the amount of power available from each of the sources discussed above, which will help in in decision making and power budget can be viewed from [11].

\subsection{Energy Storage}

The free sources of energy for harvesting is not readily available. This poses as a disadvantage, therefore different methods of storing excess power to enable supply meet demand is very crucial. Energy is usually stored in a battery or a capacitor depending on its application. The second is used when the application needs to provide huge energy spikes while the first is used when devices needs to provide a steady flow of energy because it leaks less energy[5]. In order for thin film batteries to be capable of handling the current surge when a wireless node transmits; a large capacitor or supercapacitor is paired with them. Ultra- high density supercapacitors are preferable as energy buffers in energy harvesting [2].

Supercapacitors are used in this work as storage device to provide for long term back-up power to the wireless sensor nodes and help to get rid of battery back-up units, along with its maintenance and monitoring problems. It also helps to eliminate the environmental compliance issues that comes with battery disposal, and offers superior shelf life compared to batteries. A well sized supercapacitor will last for a long period of time.

\subsubsection{Supercapacitor}

Supercapacitors are also known as electric double- layer capacitor (EDLC). Ultracapacitor is the generic name used for a family of electrochemical capacitors. Capacitors are generally constructed by placing dielectric between opposed electrodes, which acts as capacitors by storing charges. Conventionally, energy is stored in capacitors when charge carriers (electrons) are removed from one metal plate and deposited on another. The potential between the two plates is created due to the charge separation, which can be utilized in an external circuit. Supercapacitors have a rare high energy density of several orders of magnitude greater than a high capacity electrolytic capacitor compared to common capacitors, though do not have a conventional solid dielectric. It utilizes the phenomena usually known as the electric double layer. The effective thickness of the "dielectric" is extremely thin in the double layer, and because of the porous nature of the carbon the surface area is exceedingly high, which means a very high capacitance.

The following are some of the advantages of supercapacitor as a storage device.

- They have high energy storage capacity compared to conventional capacitors;

- Their equivalent series resistance (ESR) is low compared to batteries, hence providing high power density;

- The can operate in low temperature up to $-40^{\circ} \mathrm{C}$ with minimal effect on efficiency;

- They have a simple charging method;

- They have high power density;

- Very fast charge and discharge;

- They are rugged and can be operated in harsh environmental condition due to their epoxy resin sealed case which is non-corrosive;

- Improve environmental safety; 
- They have virtually unlimited cycle life.

The following are some of the disadvantages associated with supercapacitor as a storage device.

- They have a low voltage per cell, typically about $2.7 \mathrm{~V}$. In high voltage application, cells have to be connected in series;

- Due to their time constant, not suitable in Alternating and high frequency circuits.

Typically,they are used in applications where batteries have a shortfall when it comes to high power and life, and conventional capacitors cannot be used because of their inability to store enough energy. They offer a high power density along with adequate energy density for most short-term high power applications. A comparison of advantages and disadvantages of supercapacitors with other energy storage devices susc as batteries and the conventional capacitor can be found in a journal - Carbon materials for energy [9].

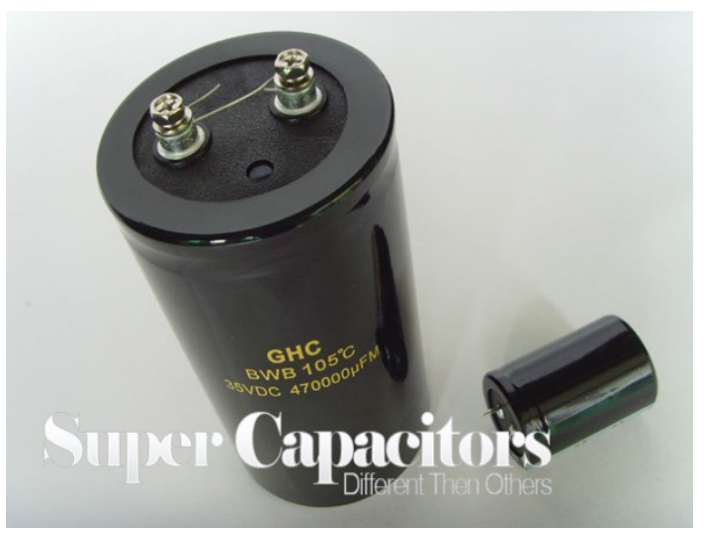

Figure 1. A real view of a supercapacitor

\section{SYSTEM DESIGN AND IMPLEMENTATION}

\subsection{System Design Specifications}

- CAP XX Supercapacitor: $1.2 \mathrm{~F}$, ESR of $50 \mathrm{~m} \Omega$, rated voltage $5.5 \mathrm{~V}$, operating voltage $(2.3$ $-2.7) \mathrm{V}$ cell.

- Sensor Node Voltage rating: $(3-5) \mathrm{V}$.

- Power and current consumption of sensor node: $32 \mathrm{~mW}$ and $8 \mathrm{~mA}$.

- Operating ambient temperature of Sensor node: $(-20 \text { to }+85)^{0} \mathrm{C}$.

- Solar panel rating: Maximum Power Voltage $=5.82 \mathrm{~V}$, Maximum Power Current $=$ $0.52 \mathrm{~A}$, Short circuit current $=0.55 \mathrm{~A}$, Open circuit voltage $=7.38 \mathrm{~V}$, Output Power tolerance $=3 \%$.

\subsection{Design Methodology}

This section gives an overview of the modules and operation of the entire system. The modules are as shown in Figure 2. 


\subsubsection{Operating Principle of the Energy harvesting wireless sensor nodes}

The functional block diagram for the intended system is shown in Figure 3.1. The voltage source (Transducer) helps in converting the solar energy into an electrical signal (voltage). The voltage source is protected by an overvoltage circuit (shunt regulator). The third stage, the charging circuit, is a current-limiter circuit, and uses MOSFET to charge the supercapacitor in the final circuit (output circuit), which in turn store the energy used to charge the sensor battery or directly supply the sensor node. The overall system is subdivided into 4 basic modules.

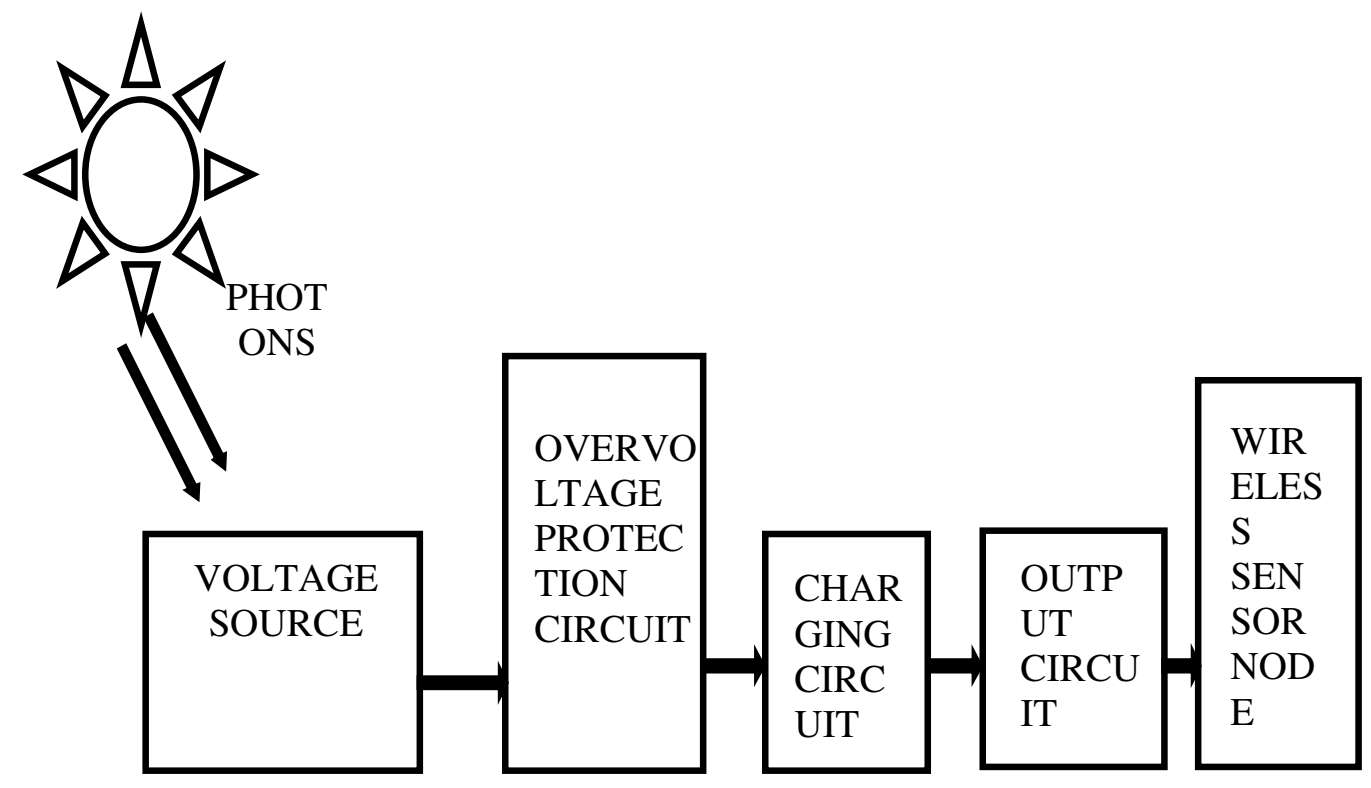

Figure 2. Block diagram of energy harvesting wireless sensor nodes

\subsubsection{Voltage Source}

Solar energy can be converted to electrical energy in the form of the voltage signal using solar cells or panel. The solar energy is as a result of illuminated junction of the cells. Its circuit model is shown in Figure 3. The current source, $I_{1}$, represents the current produced from electron-hole pair recombination due to solar radiation. The diode represents the solar cell's P-N junction characteristics. Current will pass through the solar cell just like it would pass througha diode when voltage is applied or produced across the terminals. The diode is characterized by its ideality factor, $\mathrm{n}$, and its reverse saturation current. $\mathrm{R}_{2}$ is the parallel resistance of the semiconductor materials, and diode current. $R_{1}$ is the series resistance of the metals used in the solar cell leads and contacts. Typically, $R_{2}>>R_{1}$. The solar panel operating current and voltage is $0.52 \mathrm{~A}$ and $5.82 \mathrm{~V}$ respectively. It also has an open circuit voltage of $7.38 \mathrm{~V}$. 


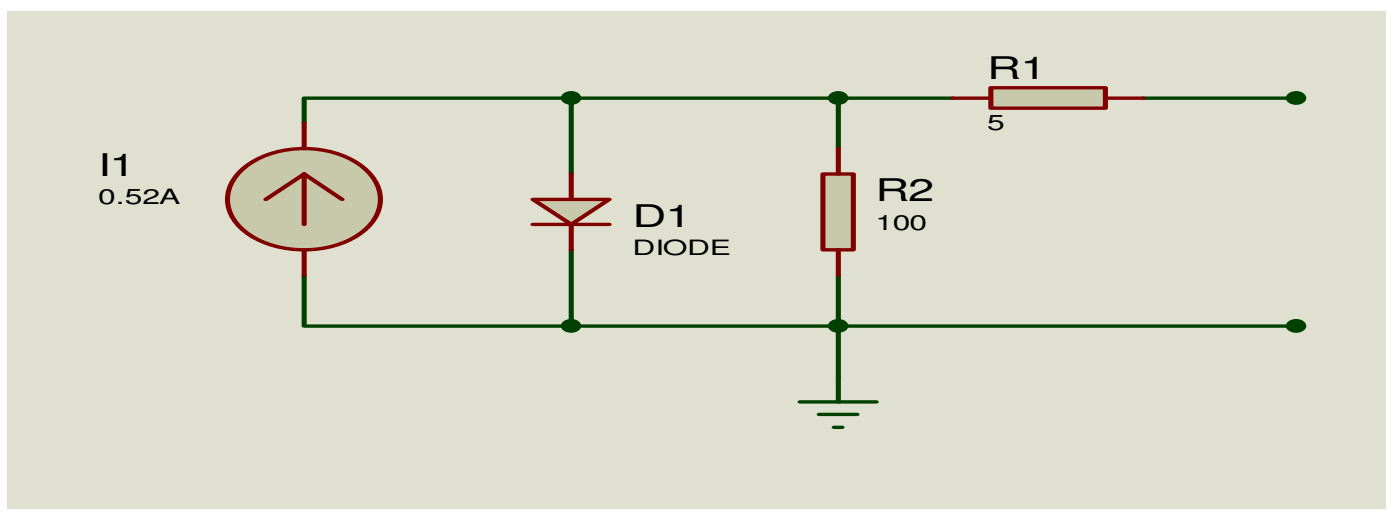

Figure 3. Solar cell circuit model

\subsubsection{Overvoltage Protection Circuit}

Supercapacitors charges best by accumulating maximum current from the source of supply since they do not charge at a constant voltage like battery does. In our design specifications, the energy source's open-circuit voltage is greater than the supercapacitor's voltage, as such, we then requires overvoltage protection for our supercapacitor using a shunt regulator. It is usually used because of its simplicity and low cost. Once the supercapacitor is fully charged, it does not matter whether the excess energy dissipates. Figure 3.3 shows the overvoltage protection circuit.

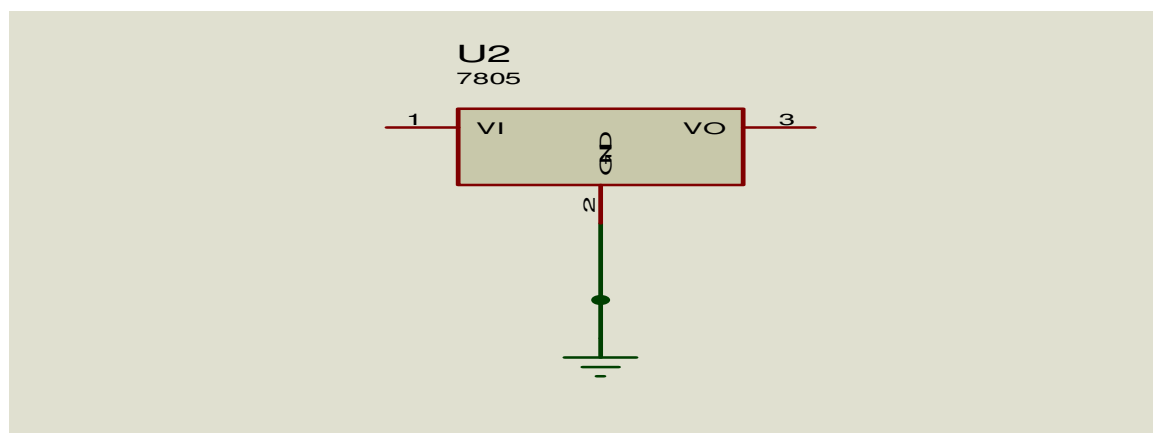

Figure 4. Fixed output voltage regulator

The voltage regulator used is $\mathrm{LM} 7805$, a $5 \mathrm{~V}, 1 \mathrm{~A}$ regulator. Since its minimum input voltage is $7 \mathrm{~V}$, it is suitable to function properly with the $7.38 \mathrm{~V}$ delivered by the solar panel and it will maintain an output voltage of $5 \mathrm{~V}$.

\subsubsection{Charging Circuit}

This is basically switching/current limiting stage. We will be using a MOSFET for this purpose. In this case, we shall be using MOSFET in load switching application. In this module, we employed CAP-XX supercapacitor with high capacitance and low ESR on the power rail, which will now serves as the load that the MOSFET will be seeing. The supercapacitor is re-charged between load pulses. We will be using MOSFET to charge the supercapacitor in a currentlimiting mode. 


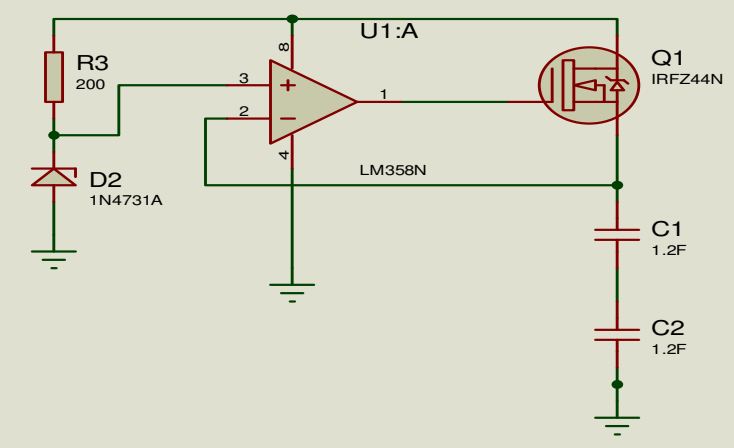

Figure 5. Simple solar cell charging circuit

The charge controller is built around the IC LM358 low power dual operational amplifier configured as a comparator. A $4.3 \mathrm{~V}$ zener diode is connected to the non-inverting input (pin 3) of the IC leading to a constant $4.3 \mathrm{~V}$ at this input pin. The zener diode current available at this pin is obtained as

$$
\mathrm{I}=\frac{V_{\text {in }}-V_{\text {out }}}{R}
$$

Where, $\mathrm{I}=$ current, $\mathrm{V}_{\text {in }}=$ input Voltage $=5 \mathrm{~V}$,

$\mathrm{V}_{\text {out }}=$ output voltage $=4.3 \mathrm{~V}$ and

$\mathrm{R}=$ Series resistance $=200 \Omega$

Therefore, $\mathrm{I}=3.5 \mathrm{~mA}$ which is greater than the typical input offset current required by the IC (i.e. 2nA).

The inverting input of the IC is connected to the capacitor charging input. Thus, when the capacitor is charging, the IC compares the capacitor charge voltage with the $4.3 \mathrm{~V}$ in pin 3 . If the charge voltage is less than $4.3 \mathrm{~V}$, the output of the comparator (pin 1) remains at a voltage of $\mathrm{Vcc}$ - $1.5 \mathrm{~V}$ (LM358 datasheet)

which is obtained as

$\mathrm{V}_{\text {out }}=\mathrm{V}_{\mathrm{cc}}-1.5 \mathrm{~V}=5-1.5=3.5 \mathrm{~V}$

This voltage serves as the gate voltage of the N-channel MOSFET IRFZ44N with ratings:

Gate to Source Voltage $V_{g s}=10 \mathrm{~V}$ at $25^{\circ} \mathrm{C}$

Continuous Drain Current $\mathrm{I}_{\mathrm{D}}=50 \mathrm{~mA}$ at $25^{\circ} \mathrm{C}$

Minimum Gate Threshold Voltage $\mathrm{V}_{\mathrm{gs}(\mathrm{th})}=2 \mathrm{~V}$

From the trans inductance curve of the MOSFET, 


$$
I_{D}=K\left(V_{g s}-V_{g s(t h)}\right)^{2}
$$

$K=\frac{I_{D}}{\left(V_{g s}-V_{g s}(t h)\right)^{2}}$

$K=780\left(m A / V^{2}\right)$

$\mathrm{K}$ is a constant, thus Drain current $\mathrm{I}_{\mathrm{D}}$, for $\mathrm{Vgs}=3.5 \mathrm{~V}$ is obtained as

$I_{D}=0.78 X(3.5-2)^{2}=1.755 A$

This means that the MOSFET can conduct up to $1.755 \mathrm{~A}$ with the input voltage of $3.5 \mathrm{~V}$ and this value is ok since only $0.52 \mathrm{~A}$ flows across the drain current.

\subsubsection{Output Circuit}

The output circuit basically consists of the supercapacitor that feeds the wireless sensor node. The supercapacitor is to power a sensor node operating at $(3-5) \mathrm{V}$. The temperature at which the nodes operate is also between $-20{ }^{\circ} \mathrm{C}$ to $+85^{\circ} \mathrm{C}$. An ideal supercapacitor circuit model is shown in Figure 6 . The supercapacitor should be sized, because, supercapacitor cells typically operate at 2.3 to $2.7 \mathrm{~V}$.

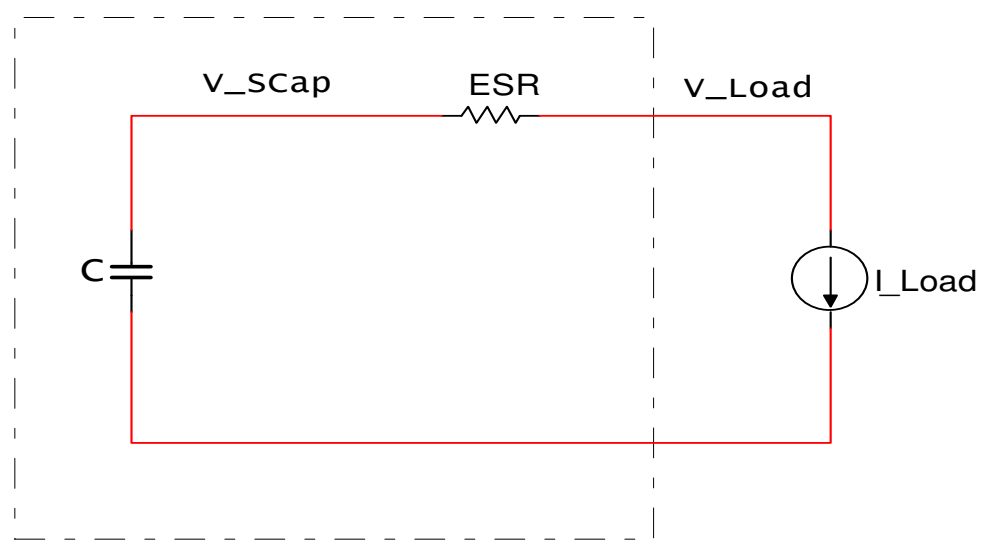

Figure 6. An ideal supercapacitor circuit model

\subsection{Modeling the Supercapacitor Discharge}

Supercapacitor cells typically operate at 2.3 to $2.7 \mathrm{~V}$. Limiting its charge voltage to less than the cell-rated voltage and storing enough energy for a particular application is most efficient and cost effective method. An easier approach method to sizing it is to calculate the energy necessary to support the peak power of the application, P.t, and set this value equal to $0.5 \times C \times\left(V_{\text {initial }}^{2}-\right.$ $\left.V_{\text {final }}^{2}\right)$, where $\mathrm{C}$ is the capacitance, $V_{\text {initial }}^{2}$ is the square of the supercapacitor's voltage just before the peak power burst, and $V_{\text {final }}^{2}$ is the square of the final voltage. But this equation does not allow for any losses in the supercapacitor's ESR (equivalent series resistance). The load sees a voltage of $V_{\text {initial }}-E S R \times I_{\text {Load }}$, where $I_{\text {Load }}$ is the load current. Due to the decrease in load voltage, the load current increases to achieve the load power. Referring to Figure 6, our supercapacitor discharge can be modelled as: 
International Journal of Wireless \& Mobile Networks (IJWMN) Vol. 6, No. 5, October 2014

$$
V_{\text {Load }}=V_{\text {Scap }}-I_{\text {Load }} \times E S R
$$

$$
\begin{array}{r}
P_{\text {Load }}=V_{\text {Load }} \times I_{\text {Load }}=\left(V_{\text {Scap }}-I_{\text {Load }} \times E S R\right) \times I_{\text {Load }} \\
=V_{\text {Scap }} \times I_{\text {Load }}-I_{\text {Load }}^{2} \times E S R
\end{array}
$$

where $\mathrm{V}_{\text {scap }}$ is the supercapacitor's voltage

The equation further leads to load current, i.e.

$$
I_{\text {Load }}^{2} \times E S R-V_{\text {Scap }} \times I_{\text {Load }}+P_{\text {Load }}=0
$$

Supercapacitor discharge can then be simply modelled using Matlab as:

$$
\begin{aligned}
& I_{\text {Load }}(t)=\left[\frac{V_{\text {Scap }}(t) \pm \sqrt{\left(V_{\text {Scap }}(t)\right)^{2}-4 \times E S R \times P_{\text {Load }}}}{2 \times E S R}\right] \\
& V_{\text {Load }}=V_{\text {Scap }}(t)-I_{\text {Load }} \times E S R \\
& V_{\text {Scap }}(t+\Delta t)=V_{\text {Scap }}(t)-\frac{I_{\text {Load }}(t) \times \Delta t}{C}
\end{aligned}
$$

\subsection{Sizing the Supercapacitor}

In order to size the supercapacitor the following variables need to be defined.

I. Maximum charged voltage (Vmax), if different from the working voltage ( $\mathrm{Vw}$ ).

II. Minimum Voltage (Vmin)

III. Power (W) or current (I) required.

IV. Discharge duration $(\mathrm{t})$

V. Duty cycle.

VI. Required life

VII. Average Operating temperature.

The last three (3) variables are used to calculate the life degradation factor to use for the supercapacitor. This is not part of the project scope. Determination of the appropriate size and also number of cells required for our application we proceed as follows:

During the discharge cycle of a supercapacitor there are two variables to look at. The voltage drop due to equivalent series resistance (ESR) and the capacitance, [10].

From [10]; Voltage drop due to the equivalent series resistance is obtained as

$$
V_{E S R}=I_{\text {Load }} \times E S
$$

Voltage drop due to the capacitance of the supercapacitor

$$
V_{S c a p}(t)=\frac{I_{L o a d}(t) \times \Delta t}{C}
$$

The total voltage drop is therefore obtained as: 
International Journal of Wireless \& Mobile Networks (IJWMN) Vol. 6, No. 5, October 2014

$$
V_{d t}=I_{\text {Load }} \times E S R+\frac{I_{\text {Load }}(t) \times \Delta t}{C}
$$

$V_{d t}$ is the total voltage drop when the capacitor is discharged. This is equal to the difference of $V_{w}$ (working voltage) and Vmin (minimum voltage) as shown in Figure 3.6. Allowing a larger $V_{d t}$ will reduce the capacitance size used. Usually by allowing the capacitor to drop to $0.5 \mathrm{Vw}, 75 \%$ of the capacitor energy is discharged.

$I_{\text {Load }}=$ current used to discharge the supercapacitor in amperes. For equation (12) we assume

$I_{\text {Load }}$ to be a constant current discharge.

$\Delta t=$ time taken to discharge the capacitor between $\mathrm{Vw}$ and Vmin in seconds.

$\mathrm{C}=$ Total capacitance of the supercapacitor in farad. If a single cell is used, then it is referred to as the cell capacitance. The equation 13 below shows the equivalent capacitance gotten from the number of capacitors in series or parallel when more than one cell is used.

$$
C=C c \times \frac{\text { Number of capacitors in parallel }}{\text { Number of capacitors in series }}
$$

$\mathrm{C}_{\mathrm{C}=}$ cell capacitance

$\mathrm{ESR}=$ total resistance of the supercapacitor in ohms. If a single cell is used, then it is called the cell resistance. The equation 14 below also shows the equivalent resistance based on the same condition as equation 13 .

$$
E S R=\text { ESRcell } \times \frac{\text { Number } \text { of resistors in series }}{\text { Number of resistors in parallel }}
$$

From the system design specification;

$$
\begin{aligned}
& \mathrm{V}_{\text {max }}=5 \mathrm{~V} \\
& \mathrm{~V}_{\text {min }}=3 \mathrm{~V} \\
& \mathrm{I}=0.008 \mathrm{~A} \\
& \mathrm{P}=0.032 \mathrm{~W}
\end{aligned}
$$

Using the values above let us determine the size of the supercapacitor.

To determine the value of our stack supercapacitor, recall that, Energy is given as

$$
P \times \Delta t=0.5 \times C \times\left(V_{\text {initial }}^{2}-V_{\text {final }}^{2}\right)
$$

Therefore, $C=\frac{2 \times P \times \Delta t}{V_{\text {initial }}^{2}-V_{\text {final }}^{2}}=\frac{2 \times 0.032 \times 150}{16}=0.6 F$

But, ESR $=$ ESRcell $\times \frac{\text { Number of resistors in series }}{\text { Number of resistors in parallel }}$

Therefore, $E S R=0.05 \times 2=0.1 \mathrm{ohms}$

From equation (12), neglecting the effect of the ESR, 
$V_{d t}=\frac{I_{L o a d}(t) \times \Delta t}{C}$, therefore $\quad \Delta t=\frac{V_{d t} \times C}{I_{\text {Load }}(t)}$

where $V_{d t}=5-3=2 \mathrm{~V}$

$$
\Delta t=\frac{2 \times 0.6}{0.008)}=150 \text { seconds }=2.5 \text { minutes } .
$$

Given $\operatorname{Vmax}=5 \mathrm{~V}$,

since each supercapacitor cell is usually rated at $2.7 \mathrm{~V}$, then we divide Vmax by 2.7 and round up.

$\frac{5}{2.7}=1.85=2$ approximated, 2 cells in series are required.

From equation (13), the cell needed will be in the range of

$C=C c \times \frac{\text { Number of capacitors in parallel }}{\text { Number of capacitors in series }}$

$C=C c \times \frac{\text { Number of capacitors in parallel }}{\text { Number of capacitors in series }}=\frac{1.2 \times 1}{2}=0.6 F$

Each of the $1.2 \mathrm{~F}$ cells will have a rated voltage of $2.7 \mathrm{~V}$, since they will be connected in series, hence the total voltage will be $5.4 \mathrm{~V}$ which will be enough to drive our wireless sensor node.

Considering the effect of ESR, from equation (12), i.e

$V_{d t}=I_{\text {Load }} \times E S R+\frac{I_{\text {Load }}(t) \times \Delta t}{C}$,

$\Delta t=\frac{\left(V_{d t}-I_{\text {Load }}(t) \times E S R\right) \times C}{I_{\text {Load }}(t)}=\frac{(2-0.008 \times 0.1) \times 0.6}{0.008}=150$ seconds $=2.5$ minutes. 


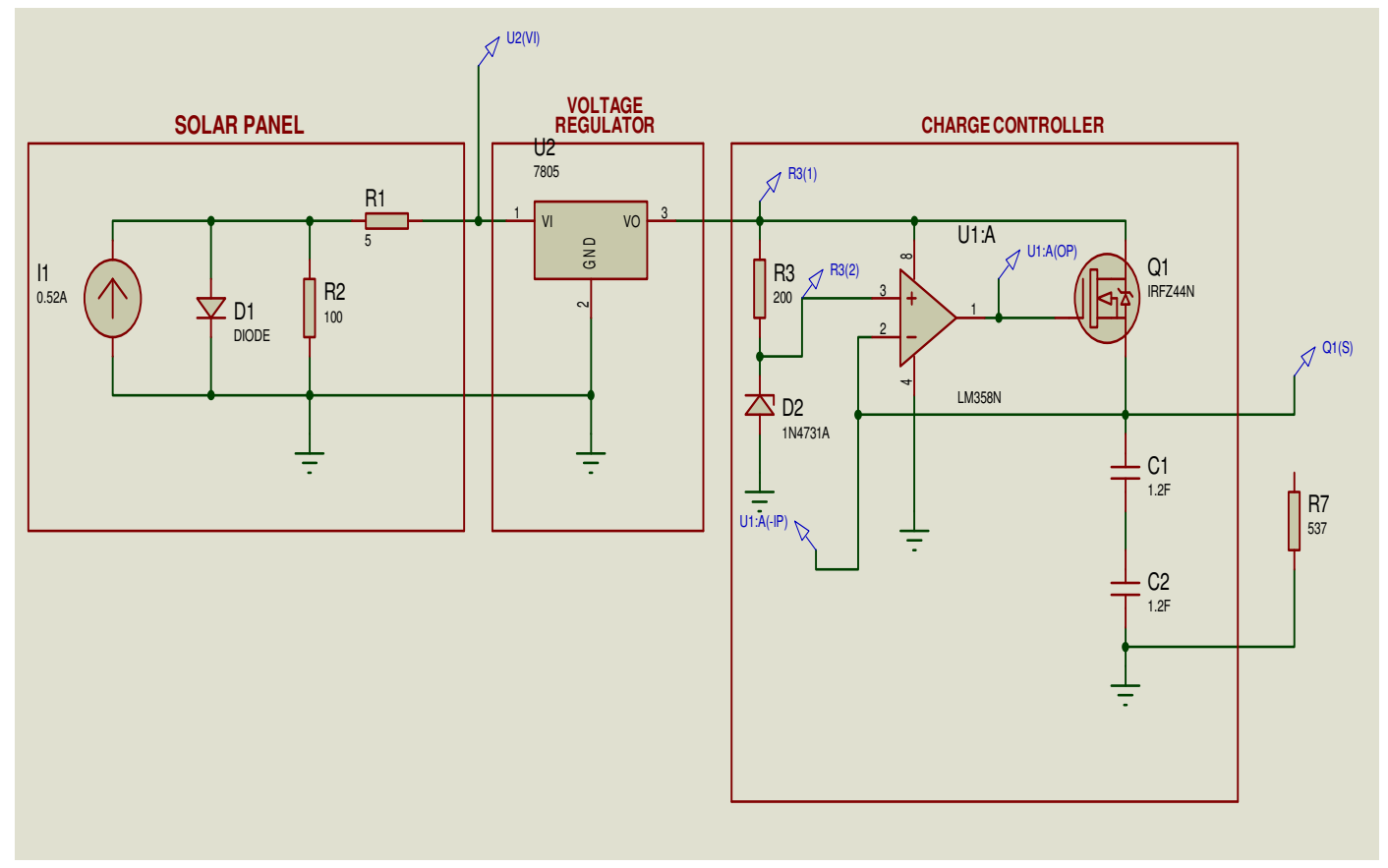

Figure 7. Overall circuit diagram of energy harvesting wireless sensor nodes

\section{Results from Modeling}

Table 1.Result of the Modeling of Supercapacitor discharge voltage

\begin{tabular}{|l|l|}
\hline Discharge Voltage (V) & Discharge duration of the capacitor (minutes) \\
\hline 5.4000 & 0 \\
\hline 4.8073 & 1 \\
\hline 4.2147 & 2 \\
\hline 3.6220 & 3 \\
\hline 3.0294 & 4 \\
\hline
\end{tabular}




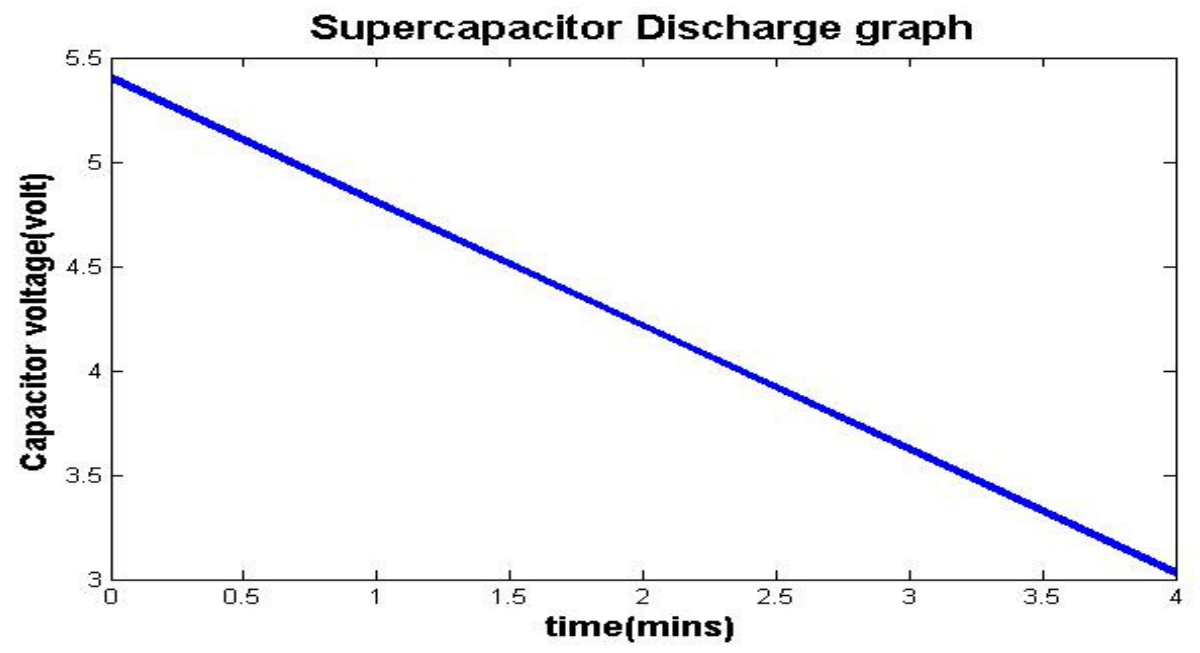

Figure 8.Supercapacitor discharge graph

\subsection{Discussion of Results}

The result obtained from the modelling of the supercapacitor discharge is as shown in Table 4.0. In the table, the maximum value the capacitor is charged to is $5.4 \mathrm{~V}$ and the minimum operating voltage which the wireless sensor node that was backed up by the capacitor can tolerate before it stops working is $3.0294 \mathrm{~V}$. The specification for the wireless sensor node requires a maximum voltage of $5 \mathrm{~V}$ and a minimum voltage of $3 \mathrm{~V}$. This implies that, only a part of the stored energy is available for applications, since the voltage drop and the time constant over the internal resistance mean that some of the charge stored cannot be accessed. The voltage drop is used in determining the size of the supercapacitor capacitance to choose for a given application. A larger drop in voltage when the capacitor is discharged will reduce the capacitance size used. When the voltage drop is more than the allowable voltage drop, the chosen capacitance is sized up and vice versa. Typically by allowing the capacitor to drop to half of the working voltage of the supercapacitor, $75 \%$ of the capacitor energy is discharged.

\subsection{CONCLUSION AND FUTURE WORK}

In conclusion, it is evident that some form of energy harvesting either from a single or multiple sources is needed for low power wireless sensor nodes- so as to reduce maintenance and prolong the lifecycle of the devices. Energy harvesting using solar cell is an interesting alternative source of energy that has the potential to provide energy independence to wireless sensor devices without the use of expensive wires, or batteries that will need replacement every now and then. From our results, it is can be said that, only a part of the stored energyis available for applications, we can now conclude that a larger drop in voltage when the capacitor is discharged will reduce the capacitance size used and this knowledge can be used to further strengthened simulation approach and practical implementation of energy harvesting wireless sensor network.

In general, there is need for optimal design considerations and energy budget for a successful implementation in any energy harvesting system. Reducing the operation of the energy of wireless sensor nodes will give room for a smaller storage capacitor value to be used, and by that, the cost of the system is reduced and sensitivity and efficiency due to the lower parasitic leakage of smaller capacitors is improved. There is a need for more than one energy harvester for a successful energy harvesting application. 


\section{REFERENCES}

[1] Stojcev, M.K., Kosanovic, M.R., and Golubovic, L.R. Power management and energy harvesting technique for wireless sensor nodes. Proceeding of the $9^{\text {th }}$ International Conference on Telecommunication in Modern Satellite, Cable, and Broadcasting Services, 2009: 65-72.

[2] John Donovan, Energy Harvesting for Lower- Power Wireless Sensor Nodes, Contributed By Convergence Promotions LLC, 2012 [online]. Available from http://www.digikey.com/enUS/articles/techzone/2012/feb/energy-harvesting-for-low-power-wireless-sensor-nodes/ [Accessed $16^{\text {th }}$ April, 2014].

[3] Aaron N. Parks, Alanson P. Sample, Yi Zhao, Joshua R. Smith. (2013). “A Wireless Sensing Platform Utilizing Ambient RF Energy" [Online]. Available from sensor.cs.washington.edu/......./wisnet_..........Accessed 17 ${ }^{\text {th }}$ April, 2014].

[4] Action Nechibvute, Albert Chawanda, and Pearson Luhanga, (2012), "Piezoelectric Energy Harvesting Devices: An Alternative Energy Source for Wireless Sensors", Smart Materials Research, Volume 2012 (2012), Article ID 853481, 13 pages [online]. Available from http://dx.doi.org/10.1155/2012/853481 [ Accessed 20 th April, 2014].

[5] Wikipedia. (2014). Energy harvesting [online]. Available from http://en.wikipedia.org/wiki/Energy_harvesting/ [Accessed 6th April, 2014].

[6] [online] available at http://en.wikipedia.org/wiki/Thermoelectrics\#cite_note-14

[7] Wikipedia. (2014). Supercapacitor [online]. $\quad$ Available from http://en.wikipedia.org/wiki/Supercapacitor/ [Accessed 6th April, 2014].

[8] http://www.tecategroup.com/ultracapacitors-supercapacitors/ultracapacitorsFAQ.php\#What_is_an_ultracapacitor

[9] Pierre Mars (2012). "Coupling a Supercapacitor with a Small Energy Harvesting Source",Published in EE Times Design [online]. Available from http://www.cap-xx.com [Accessed 18 ${ }^{\text {th }}$ April, 2014].

[10] Maxwell Technology Applications Note: Ultracapacitor Cell.

[11] Adamu Murtala Zungeru, Li-Minn Ang, SRS. Prabaharan, Kah Phooi Seng (2012), "Radio Frequency Energy Harvesting and Management for Wireless Sensor Networks”, Publisher: CRC Press, Taylor and Francis Group, USA, [online], Available: http://www.crcnetbase.com/doi/abs/10.1201/b10081-16.

\section{Authors}

Hussaini Habibu received his B.Eng. degree in Electrical and Computer Engineering from the Federal University of Technology (FUT) Minna, Nigeria in 2010. He is a Graduate Assistant Lecturer at the Federal University of Technology Minna, Nigeria from 2012-till date.

His area of research includes energy systems and electrical power and machines. He is currently an MSc student at the department of

Electronics and Computer Science (ECS), University of Southampton, United Kingdom.

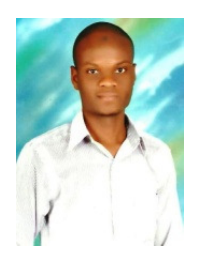

Abimbola Susan Ajagun received her B.Eng. degree in Electrical and Computer Engineering from Federal University of Technology (FUT) Minna, Nigeria in 2010. She is a Graduate Assistant Lecturer at the Federal University of Technology Minna, Nigeria from 2012-till date. Her area of research includes energy systems and power system protection. She is currently a MEng. student at the department of Electrical and Electronics Engineering, Federal University of technology, Minna, Nigeria.

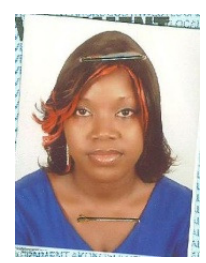


Gerald K. Ijemaru received his B.Eng. degree in Electrical and Electronics Engineering from Enugu State University of Science \& Technology (ESUT), Nigeria in 2004, and M.Sc. Degree from the Coventry University, U.K, in 2010. Engr. G. K. Ijemaru is a member of the Institute of Information \& Communication Technology Development (ICTD), UK. He is at present, a Lecturer II and researcher with the department of Electrical and Electronics Engineering, Federal University Oye-Ekiti, Nigeria, with interest in Challenges regarding MIMO in $3 \mathrm{G}$ Cellular Systems, Antennas for MIMO

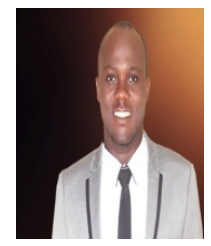
systems, Control systems design and applications and a Space Diversity Technique for Combating Signal Fading. He has published in reputable Journals.

Dr. Engr. Adamu Murtala Zungeru received his B.Eng. Degree in Electrical and Computer Engineering from the FUT Minna, Nigeria in 2004, and M.Sc. Degree in Electrical Engineering from the ABU Zaria, Nigeria in 2009, PhD Degree from the University of Nottingham in 2013 and Postdoctoral Teaching Certificate from the MIT USA in 2014. He is, at present, a Senior Lecturer at the Federal University Oye-Ekiti, Nigeria, and the Head of Department of Electrical and Electronics Engineering. He is a registered Engineer with the COREN, Member of the IEEE and ACM, and the Inventor of Termite-hill routing algorithm for WSN. He has served as Session Chair, ICSI-2012;

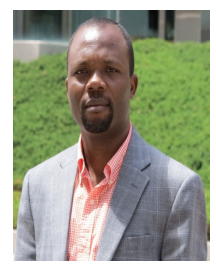
Technical Program Committee Member, IEEE-WCNC 2013 \& 2014; ICCVE 2013; ICIT 2014; CEIT'13 2013; SPPR 2014; Ubic-2014; WiMoA 2014; InWeS-2014; CYBI 2014; SCAI 2014; WiMoNe-2014; ARIA 2015; SIP 2015. He is an editorial board member of the International Journal of Networking; IJICS; IJSET; IJCSIT. He has also served as an International reviewer to IEEE Transaction on Industrial Informatics; IEEE Sensors; JNCA, ELSEVIER; Wireless Networks Springer; IET Networks Journal; Sensors MDPI; Simulation-transaction of the society for modelling and simulation international; International Journal of communication systems, Wiley; Journal of Sensors, Hindawi; and numerous others. His research interests are in the fields of automation, swarm intelligence, wireless sensor networks (WSNs), energy harvesting, and energy management, where he has published over 30 International articles. He has done extensive research on the design of routing algorithms for WSNs, and at present looking at the application of the algorithms designed for WSN in solving World problems. 